\title{
Liriodenine and its Therapeutic Potential
}

\author{
José del Carmen Rejón Orantes* and Karina Janeth Gómez Vázquez \\ Faculty of Human Medicine, Universidad Autónoma de Chiapas, Mexico
}

*Corresponding author: José del Carmen Rejón Orantes, Pharmacobiology Experimental Laboratory, Faculty of Human Medicine, Universidad Autónoma de Chiapas, Mexico.

To Cite This Article: José del Carmen Rejón Orantes, Liriodenine and its Therapeutic Potential. 2020 - 7(4). AJBSR.MS.ID.001171.

DOI: 10.34297/AJBSR.2020.07.001171.

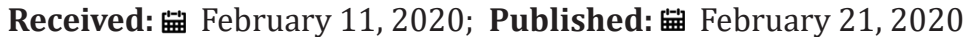

\section{Introduction}

Liriodenine is an alcaloid BIQ isolated for the first time from the Liriodendron tulupifera [1] and subsequently from Rutaceae,

Magnoliaceae, Monimiaceae, Menispermaceae, Annonaceae families, etc. [2] (Figure 1).

Figure 1: Liriodenine structure

Liriodenine is an alcaloid that has a wide range of biological activities, including antimicrobial, anticancer, cardiovascular effects and affinity for some receptors, is a promising potential drug candidate for the treatment of multiple ailments.

Antimicrobial activities. Liriodenine has antimicotic effects, that were determinated in the candidiasis mice model [3]. Also, against various microorganisms' activity (Streptococcus, Staphylococcus, Bacillus, Lysteria, Escherichia, Salmonella, Klebsiella, Pseudomonas, Enterobacter, Serratia, Shigella, Mycobacterium y Plasmodium falciparum) [4,5].

Anticancer activity. In order to explain the cytotoxic activity of liriodenine in neoplastic cells various levels of action have been proposed; topoisomerase II inhibition, cell cycle blocking and apoptosis inducing. In CV-1 cells infected with CV40, liriodenine inhibit topoisomerasa II, the necessary enzyme for the DNA replication and separation of recent replicas in eukaryotic cells chromosomes [6]. In pulmonary adenocarcinoma human cells (A549) liriodenine blocked the celular cycle progression in the
G2/M phase by the accumulation pathway in the G2 phase of cyclines (B1) and the kinase activity inhibition of the B1/CDK1 complex. Cyclines, cyclin dependent kinases (CDKs), and cyclin dependent inhibitory kinases (CDKIs) are involved in cell cycle progression [7]

Liriodenine caused cell death by activation of caspases. In A549 cells with this alkaloid treatment the PARP protein degradation was observed, this protein is a substrate for several caspases, presenting the induction of apoptosis, the number of apoptotic cells

(PI-negative and annexin-V-positive) increased after treatment with liriodenine [7]. In ovarian cancer induced apoptosis in CAOV3 cells via the mitochondrial signaling pathway by involvement of caspase-3 and caspase-9 [8].

Liriodenine inhibited the human hepatoma cells proliferation, from Hep G2 and SK-Hep-1 cell lines, blocking the cell cycle in the transition of the G1-S phase in a dose-dependent manner. On the other hand, liriodenine increases intracellular nitric oxide (ON) 
levels simultaneously with the blocking of G1 phase of the cell cycle in Hep G2 cells. ON is an inhibitor of cell proliferation and reversibly inhibits DNA synthesis [9]. At low concentrations, ON induces cell growth and protects many cell types from apoptosis, at high concentrations it inhibits cell growth and induces apoptosis [9].

Liriodenine exhibited potent antitumor activities in laryngocarcinoma HEp-2 cells, via the upregulation of p53 expression which induced cell apoptosis, and attenuation of the rate of tumor growth and increased inhibition of cell migration in HEp2 cells [10]. Furthermore, increased the number of p-53- positive cells in human hepatoma cells (9). Decreased cellular viability, inducing the apoptotic rate, increasing the formation of apoptotic nucleoli and the caspase- 3 activity of MCF-7 cells. The potential mechanism underlying the antitumor effects of liriodenine may result from inhibition of Bcl-2, cyclin D1 and VEGF expression, and up regulation of p53 expression, which ultimately induces cellular apoptosis [11].

Combined with radiation therapy, induced a significant decrease in the viability and proliferation of esophageal squamous cell carcinoma cells, induces apoptosis of radioresistant esophageal squamous cell carcinoma cell lines by increasing expression of Bax and caspase-3, and decreasing that of Bcl-2 [12]. One platinum (II) complex of liriodenine (as TCM active ingredient) with significant growth inhibition against BEL-7404 human hepatoma cell line was confirmed [13].

Cardiovascular effects. It was found in electrophysiological studies using rat heart muscle isolated strips, that liriodenine blocks the $\mathrm{Na}^{+}$and $\mathrm{K}^{+}$channels, prolongs the action potential by increasing $\mathrm{Ca}^{++}$entry and can suppress the ventricular arrhythmia [14]. These results place liriodenine as a potential antiarrhythmic agent. Moreover, in the ischemia and reperfusion Langendorff model using Sprague-Dawley rat heart, this alkaloid significantly promoted the recovery of coronary flow and decreased myocardial infarction compared to the control group $[15,16]$.

Effects on some receptors. Liriodenine behaved as an M3 muscarinic antagonist, the effects of this alkaloid in tests of radio-ligand displacement and relaxation of the smooth muscle of the canine trachea-induced agonist were similar to those of 4-diphenylacetoxy-N-methylpiperidine, a selective antagonist for M3 receptors [17]. On the other hand, liriodenine caused relaxation of the contraction induced by norepinephrine in the rat aorta, it suggests that it also has alpha1 antagonistic activity [18]. Finally, inhibited dopamine in situ synthesis and release [19].

\section{References}

1. Buchanan MA, Dickey EE (1960) Liriodenine, A Nitrogen-Containing Pigment of Yellow Poplar Heartwood (Liriodendron tulipifera, L. J Org Chem 25(8): 1389-1391.

2. Guinaudeau H, Leboeuf M, Cavé A (1988) Aporphinoid Alkaloids, IV. J Nat Prod 51(3): 389-474.
3. Clark A, Watson ES, Ashfaq K, Hufford C (1987) In Vivo Efficacy of Antifungal Oxoaphorfine Alkaloids in Experimental Disseminated Candidiasis. Pharm Res 4(6): 495-498.

4. Villar A, Mares M, Rios JL, Canton E, Gobernado M (1987) Antimicrobial activity of benzylisoquinoline alkaloids. Pharmazie 42(4): 248-250.

5. Mbah JA, Tane P, Ngadjui BT, Connolly JD, Okunji CC, et al. (2004) Antiplasmodial agents from the leaves of Glossocalyx brevipes. Planta Med 70(5): 437-440.

6. Woo SH, Reynolds MC, Sun NJ, Cassady FM, Snapku RM (1997) Inhibition of Topoisomerase II by Lyriodenine. Biochem Pharmacol 54(4): 467473.

7. Chang W, Cheng CH, Wu Y, Su M (2004) The vascular and cardioprotective effects of liriodenine in ischemia-reperfusion injury via NO-dependent pathway. Nitric Oxide 11(4): 307-315.

8. Noraziah Nordin, Nazia Abdul Majid, Najihah Mohd Hashim, Mashitoh Abd Rahman, Zalila Hassan, et al. (2015) Liriodenine, an aporphine alkaloid from Enicosanthellum pulchrum, inhibits proliferation of human ovarian cancer cells through induction of apoptosis via the mitochondrial signaling pathway and blocking cell cycle progression. Drug Design Development and Therapy 9: 1437-1448.

9. Hsieh TJ, Liu TZ, Chern CL, Tsao DA, Lu FJ, et al. (2005) Liriodenine inhibits the proliferation of human hepatoma cells lines by blocking cell cycle progression and nitric oxide-mediated activation of p53 expression. Food Chem Toxicol 43(7): 1117-1126.

10. Liang Li, Ying $\mathrm{Xu}$, Binquan Wang (2015) Liriodenine induces the apoptosis of human laryngocarcinoma cells via the upregulation of p53 expression. Oncology Letters 9(3): 1121-1127.

11. Zhi Hua Li, Jin Gao, Ping Hua Hu, Jian Ping Xiong (2017) Anticancer effects of liriodenine on the cell growth and apoptosis of human breast cancer MCF-7 cells through the upregulation of p53 expression. Oncology Letters 14(2): 1979-1984.

12. Gang Wu, Guangzong Chen, Jialiang Zhou, Hongcheng Zhu, Jianjun Chu, et al. (2018) Liriodenine enhances radiosensitivity in esophageal cancer ECA-109 cells by inducing apoptosis and G2/M arrest. Oncology Letters 16(4): 5020-5026.

13. Yu Lan Li, Qi Pin Qin, Yan Cheng Liu, Zhen Feng Chen, Hong Liang (2014) A platinum (II) complex of liriodenine from traditional Chinese medicine (TCM): Cell cycle arrest, cell apoptosis induction and telomerase inhibition activity via G-quadruplex DNA stabilization. Journal of Inorganic Biochemistry 137: 12-21.

14. Chang GJ, WU MH, Wu YC, Su MJ (1996) Electrophysiological mechanisms for antiarrhythmic efficacy and positive inotropy of liriodenine, a natural aporphine alkaloid from Fissistigma glaucescens. Br J Pharmacol 118(7): 1571-1583.

15. Chang KC, Su MJ, Peng YI, Shao CC, Wu YC, et al. (2001) Mechanical effects of liriodenine on the left ventricular-arterial coupling in Wistar rats: pressure-stroke volume analysis. Br J Pharmacol 133(1): 29-36.

16. Chang W, Cheng CH, Wu Y, Su M (2004) The vascular and cardioprotective effects of liriodenine in ischemia-reperfusion injury via NO-dependent pathway. Nitric Oxide 11(4): 307-315.

17. Lin CH, Yang CM, KO FN, Wu YC, Teng CM (1994) Antimuscarinic action of liriodenine, isolated from Fissistigma glaucescens, in canine tracheal smooth muscle. Br J Pharmacol 113(4): 1464-1470.

18. Chulia S, Noguera MA, Ibarra MD, Cortes D, D Ocon P (1995) Vasodilator effects of liriodenine and norushinsunine, two aporphine alkaloids isolated from Annona cherimolia, in rat aorta. Pharmacology 50(6): 380-387.

19. Jin CM, Lee JJ, Yang YJ, Kim YM, Kim YK, et al. (2007) Liriodenine Inhibits Dopamine Biosynthesis and L-DOPA Induced Dopamine Content in PC12 Cells. Arch Pharm Res 30(8): 984-990. 